\title{
Chalcone derived benzoheterodiazepines for medicinal applications: A Two-pot and one-pot synthetic approach
}

\author{
Saba Farooq ${ }^{\circledR}$ | Zainab Ngaini $\odot$
}

Faculty of Resource Science and

Technology, Universiti Malaysia Sarawak, Kota Samarahan, Malaysia

\section{Correspondence}

Saba Farooq and Zainab Ngaini, Faculty

of Resource Science and Technology,

Universiti Malaysia Sarawak, 94300 Kota

Samarahan, Sarawak, Malaysia.

Email: sabafarooq61@yahoo.com (S. F.)

and nzainab@unimas.my (Z.N.)

\section{Funding information}

Ministry of Higher Education, Grant/ Award Number: F07/FRGS/1883/2019; Universiti Malaysia Sarawak, Grant/ Award Number: F07/PGRS/1794/2019

\begin{abstract}
The production of effective drugs has continuously been a challenging process for researchers due to the occurrence of resistive diseases. Drugs derived from natural product-based compounds as an active scaffold have gained interest in drug development due to a wide range of biological properties. Benzoheterodiazepines, a natural product derivative of bicyclic chalcones have been widely reported with various therapeutic potentials. This review discusses current synthetic methods in the preparation of benzoheterodiazepine derivatives (i.e., homocyclic benzoheterodiazepine, heterocyclic benzoheterodiazepine, bisbenzoheterodiazepine, and fused benzoheterodiazepine) via two-pot and one-pot synthetic routes. Several reaction protocols following both synthetic routes have been developed for efficient and higher yields that offer access to different functionalization of benzoheterodiazepines are comprehensively described. This review is important in the heterocyclic chemistry of benzoheterodiazepines and pharmacological industries in drug development processes.
\end{abstract}

\section{1 | INTRODUCTION}

Chalcone is a natural product [1] and bio-active [2,3] molecule that frequently used in the synthesis of heterocyclic compounds that is, pyrazole [4], imidazole [5,6], epoxide [7], benzodiazepine [8], pyrimidine [9], indole [10], flavone [11], isoflavone [12], and pyrazoline [13-15]. Chalcone-derived heterocyclic compounds consist of heteroatomic atoms (i.e., oxygen, sulfur, and nitrogen), which remarkable in the medicinal field for excellent activities in drug design [16-18]. Benzoheterodiazepine is a seven-membered heterocyclic ring [19] with two heteroatoms [20], nonplanar [21], and pharmacophoric [22,23] properties. Benzodiazepines and benzothiazepines are examples of benzoheterodiazepine derivatives that are commercially used in medicine such as nevirapine [24], fuligocandin B [25], tiazesim [26], halazepam [27], diltiazem [28], triazolam [29], gastrozepin [30], clozapine (a) [31], olanazapine (b) [32], 3-carbamoyl-1,5-benzodiazapine (c), clobazam (antiepileptic agent), (d) and neoplasm inhibitors (e) (Figure 1) [31,33].
Benzodiazepines and benzothiazepines played a prominent role in drug research during the last three decades [34]. Their derivatives are also equally significant in pharmaceutical applications with a wide spectrum of biological properties such as antiinfectives [35], antiarrhythmic [36], anthelmintic [37], anticancer [38-42], antifidant [43], antihypnotic [44], antihypertensive [45], anticonvulsant [46,47], antioxidant [48,49], antidiabetic [50], antiHIV [24,51,52], antifungal [53], antidepressant [54], antimicrobial [55], antituberculosis [18], antineoplastics [56], anti-inflammatory [57] as well as inhibitors for cholinesterase [58] and neurological disorders [59]. Benzoheterodiazepine derivatives have also been reported as corrosion inhibitors [60], dyes for the acrylic fibers [57] in photography, photographic emulsions [61], and lubricating oil with antioxidant properties [62]. The 1,5-benzodiazepine is the active chromophore of benzoheterodiazepines against different types of targets including interleukin converting enzymes, peptide hormones, and potassium blockers [63]. 
SCHEME 18 One-pot synthesis of benzoheterodiazepine derivatives

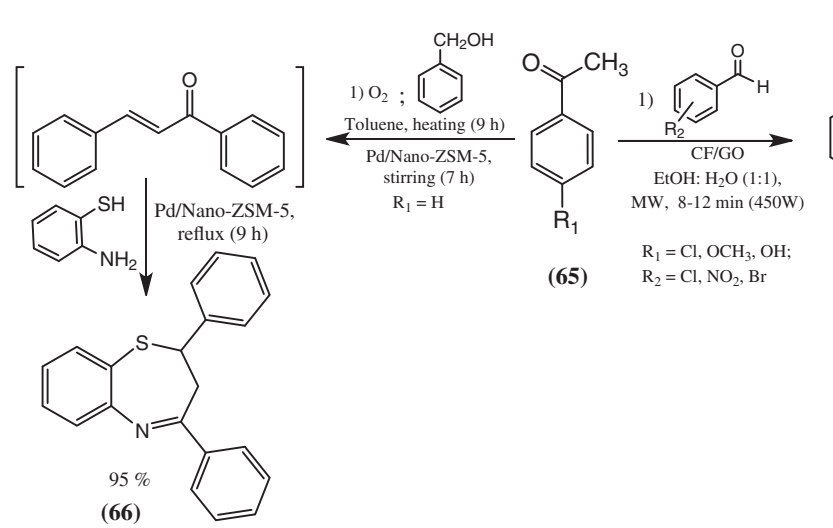

\section{3 | CONCLUSION}

Benzoheterodiazepines are one of the heterocyclic compounds with reactive pharmacophore and a wide range of biological properties. Researchers are tirelessly working around the clock in designing and modifying benzoheterodiazepines nucleus to produce series of effective drugs. This updated review article is based upon the chalcone-derived benzoheterodiazepines synthetic routes (i.e., one-pot and two-pot) and their applications. Two-pot is commonly used with several advantages such as less solvent usage, good purity of desired product, and a lower rate of side product formations compared to one-pot synthetic methodology. Nevertheless, the one-pot synthetic route offers a faster reaction with no purification step of intermediates involved. The assembled information regarding chalcone-derived benzoheterodiazepine synthesis and its applications is significant among synthetic chemists and pharmacists in designing drugs with fascinating medicinal properties.

\section{ACKNOWLEDGMENTS}

The author is grateful to the Ministry of Higher Education Malaysia through F07/FRGS/1883/2019 and Universiti Malaysia Sarawak through F07/PGRS/1794/2019 for financial support for this project.

\section{DATA AVAILABILITY STATEMENT}

No data is available for the research work.

\section{ORCID}

Saba Farooq (10) https://orcid.org/0000-0002-0159-9540 Zainab Ngaini (1) https://orcid.org/0000-0001-7243-6856

\section{REFERENCES}

[1] V. R. Yadav, S. Prasad, B. Sung, B. B. Aggarwal, Int. Immunopharmacol. 2011, 11, 295. https://doi.org/10.1016/j. intimp.2010.12.006
[2] J. C. Aponte, M. Verástegui, E. Málaga, M. Zimic, M. Quiliano, A. J. Vaisberg, R. H. Gilman, G. B. Hammond, J. Med. Chem. 2008, 51, 6230. https://doi.org/10.1021/ jm800812k

[3] A.-M. Katsori, D. Hadjipavlou-Litina, Expert. Opin. Ther. Pat. 2011, 21, 1575. https://doi.org/10.1517/13543776.2011.596529

[4] S. Farooq, Z. Ngaini, Curr. Org. Chem. 2020, 24, 1491.

[5] S. Ponnala, D. Prasad Sahu, Synth. Commun. 2006, 36, 2189. https://doi.org/10.1080/00397910600638879

[6] P. S. Bhale, S. B. Dongare, U. B. Chanshetti, Res. J. Chem. Sci. 2013, 3, 38.

[7] S. Farooq, Z. Ngaini, Chem. Afr. 2020, 3, 291. https://doi.org/ 10.1007/s42250-020-00128-5

[8] W.-G. Chai, G.-H. Wang, S. Jin, Z.-M. Lin, P. Liu, Org. Mass Spectrom. 1987, 22, 660. https://doi.org/10.1002/oms. 1210221004

[9] S. Farooq, Z. Ngaini, J. Heterocyclic Chem. 2021, 58, 12091224. jhet.4226. https://doi.org/10.1002/jhet.4226

[10] S. Farooq, Z. Ngaini, Curr. Organocatal. 2019, 6, 184.

[11] N. Mateeva, M. Gangapuram, E. Mazzio, S. Eyunni, K. F. A. Soliman, K. K. Redda, Med. Chem. Res. 2015, 24, 1672. https://doi.org/10.1007/s00044-014-1214-7

[12] L. Wang, X. Yang, Y. Zhang, R. Chen, Y. Cui, Q. Wang, J. Nat. Prod. 2019, 82, 2761. https://doi.org/10.1021/acs. jnatprod.9b00365

[13] S. Farooq, Z. Ngaini, ChemistrySelect 2020, 5, 9974. https:// doi.org/10.1002/slct.202002278

[14] S. Farooq, Z. Ngaini, N. A. Mortadza, Bull. Kor. Chem. Soc. 2020, 41, 918. https://doi.org/10.1002/bkcs.12088

[15] S. Farooq, Z. Ngaini, Tetrahedron Lett. 2020, 61, 151416. https://doi.org/10.1016/j.tetlet.2019.151416

[16] N. S. Chowdari, Y. Zhang, I. McDonald, W. Johnson, D. R. Langley, P. Sivaprakasam, R. Mate, T. Huynh, S. Kotapati, M. Deshpande, C. Pan, J. Med. Chem. 2020, 63, 13913-13950. https://doi.org/10.1021/acs.jmedchem.0c01385

[17] A. K. Singh, V. Raj, A. Rai, A. K. Keshari, S. Saha, Future Sci. OA 2017, 3, FSO168. https://doi.org/10.4155/fsoa-2016-0079

[18] P. Palanisamy, S. J. Jenniefer, P. T. Muthiah, S. Kumaresan, RSC Adv. 2013, 3, 19300. https://doi.org/10.1039/c3ra42283f

[19] A. Szöllösy, G. Kotovych, G. Tóth, A. Lévai, Can. J. Chem. 1988, 66, 279. https://doi.org/10.1139/v88-047

[20] X. Huang, J. Xu, Heteroat. Chem. 2003, 14, 564. https://doi. org/10.1002/hc.10196 